\title{
Alcohol and ischaemic heart disease in middle aged British men
}

\author{
A G SHAPER, A N PHILLIPS, S J POCOCK, M WALKER
}

\begin{abstract}
The relation between alcohol intake and ischaemic heart disease was examined in a large scale prospective study of middle aged men drawn from general practices in 24 British towns. After an average follow up of 6.2 years 335 of the 7729 men had experienced a myocardial infarction (fatal or non-fatal) or sudden cardiac death. No significant relation was found between reported alcohol intake and the incidence of such events. Though the group of light daily drinkers had the lowest incidence of ischaemic heart disease events, it also contained the lowest proportion of current smokers, had the lowest mean blood pressure, had the lowest mean body mass index, and contained the lowest proportion of manual workers. These characteristics are more likely to account for the apparent protective effect of alcohol against ischaemic heart disease than a direct effect of alcohol.

Compared with the effects of established risk factors alcohol seems to be quite unimportant in the development of ischaemic heart disease.
\end{abstract}

\section{Introduction}

Heavy drinking has long been known to damage the heart, and the concept of alcoholic cardiomyopathy is well recognised, though this is not a diagnosis often made in Britain. ${ }^{1}$ It is also becoming more widely recognised that there is a strong association between heavy drinking and hypertension. ${ }^{2}$ Most widely accepted, however, is the belief that light or moderate drinking is beneficial, or "protective," in relation to ischaemic heart disease. ${ }^{34} \mathrm{We}$ examine here the relation between alcohol consumption and ischaemic heart disease in middle aged men taking part in the British regional heart study, a large prospective study of cardiovascular disease.

\footnotetext{
Department of Clinical Epidemiology and General Practice, Royal Free Hospital School of Medicine, London NW3 2PF

A G SHAPER, FRCP, FRCPATH, professor of clinical epidemiology

A N PHILLIPS, MSC, PHD, statistician

S J POCOCK, MSC, PHD, reader in medical statistics

$M$ WALKER, MA, SRN, research administrator

Correspondence to: Professor Shaper.
}

\section{Subjects and methods}

The British regional heart study includes 7735 men aged 40-59 selected randomly from the age-sex registers of one group general practice in each of 24 towns in England, Wales, and Scotland. ${ }^{5}$ The general practice selected in each town has a social class distribution representative of the men of that town:

From the age-sex register of each practice some 420 men aged 40-59 were selected at random into stratified five year age groups of equal size. The list of names was reviewed by the doctors in the practice, and only those who were not able to participate because of severe mental or physical disability were excluded: about six to $\mathbf{1 0}$ men in each practice were excluded for this reason. The general practitioner signed a letter inviting the men to take part, and $78 \%$ of those invited attended for examination. Research nurses filled in their answers to an extensive questionnaire that included questions on alcohol consumption as part of a general inquiry into dietary, drinking, and smoking habits. The men were asked whether a doctor had ever told them that they were suffering from any disorder on a given list, and they were also asked about details of any regular drug treatment. Several physical measurements were made, a resting electrocardiogram recorded, and blood samples taken for biochemical and haematological tests.

\section{ALCOHOL INTAKE}

On the basis of their answers to questions about frequency and quantity of alcohol intake the men were grouped into eight drinking categories: nondrinkers, occasional drinkers (special occasions or once or twice a month), weekend drinkers (one or two, three to six, or more than six drinks a day), and men drinking daily or on most days (one or two, three to six, or more than six drinks a day). A drink was defined as a half pint of beer, one glass of wine or sherry, or a single tot of spirits. No questions were asked about previous drinking habits. Data for six men were missing. The terms "light" (one or two drinks), "moderate" (three to six), and "heavy" (more than six) are used when describing both daily and weekend drinkers. The two heavy drinking categories are open ended, and therefore it was not possible to estimate precisely the average daily intakes for men in these categories. There were also important differences in the distribution of risk factors (cigarette smoking, systolic blood pressure, social class) between weekend and daily drinkers within each quantity group (see table I). We therefore present the data in eight categories rather than attempting to use a single quantitative variable—for example, $g$ alcohol/day.

The reported alcohol consumption was compared with 25 biochemical and haematological measurements performed on a single blood sample taken when the questionnaire was completed. 6 Several measurements showed substantial dose-response relations with the reported alcohol consumption, including $\gamma$-glutamyltransferase activity, concentrations of high densitv 
TABLE I-Drinking categories and their relation to risk factors for ischaemic heart disease

\begin{tabular}{|c|c|c|c|c|c|c|c|c|}
\hline & \multirow[b]{3}{*}{ None } & \multirow[b]{3}{*}{ Occasional } & \multicolumn{6}{|c|}{ No of drinks } \\
\hline & & & \multicolumn{3}{|c|}{ Weekend } & \multicolumn{3}{|c|}{ Daily } \\
\hline & & & $1-2$ & $3-6$ & $>6$ & $1-2$ & $3-6$ & $>6$ \\
\hline $\begin{array}{l}\text { No }(\%) \text { of subjects } \\
\text { Mean age (years) } \\
\text { No }(\%) \text { of current smokers } \\
\text { Smoking years } \\
\text { Blood pressure }(\mathrm{mm} \mathrm{Hg}):\end{array}$ & $\begin{array}{c}466(6) \\
51 \cdot 4 \\
172(37) \\
19 \cdot 1\end{array}$ & $\begin{array}{c}1845(24) \\
50 \cdot 3 \\
738(40) \\
19 \cdot 5\end{array}$ & $\begin{array}{c}725(9) \\
50 \cdot 7 \\
225(31) \\
17 \cdot 2\end{array}$ & $\begin{array}{c}1234(16) \\
50 \cdot 0 \\
494(40) \\
20.3\end{array}$ & $\begin{array}{c}1095(14) \\
49 \cdot 0 \\
591(54) \\
24 \cdot 5\end{array}$ & $\begin{array}{c}585(8) \\
51 \cdot 0 \\
129(22) \\
16 \cdot 2\end{array}$ & $\begin{array}{c}947(12) \\
50 \cdot 3 \\
369(39) \\
21 \cdot 5\end{array}$ & $\begin{array}{l}832(11) \\
49 \cdot 6 \\
474(57) \\
25 \cdot 5\end{array}$ \\
\hline $\begin{array}{l}\text { Systolic } \\
\text { Diastolic } \\
\text { Serum cholesterol (mmol/l) } \\
\text { High density lipoprotein cholesterol (mmol/l) } \\
\text { Mean body mass index }\left(\mathrm{kg} / \mathrm{m}^{2}\right) \\
\text { No }(\%) \text { of "obese" subjects } \\
\text { No (\%) of manual workers }\end{array}$ & $\begin{array}{l}144 \\
81 \\
6 \cdot 2 \\
1 \cdot 04 \\
25 \cdot 4 \\
98(21) \\
312(67)\end{array}$ & $\begin{array}{c}144 \\
81 \\
6 \cdot 3 \\
1 \cdot 05 \\
25 \cdot 3 \\
351(19) \\
1033(56)\end{array}$ & $\begin{array}{l}144 \\
81 \\
6 \cdot 3 \\
1 \cdot 10 \\
25 \cdot 2 \\
109(15) \\
312(43)\end{array}$ & $\begin{array}{l}145 \\
82 \\
6 \cdot 3 \\
1 \cdot 11 \\
25 \cdot 5 \\
247(20) \\
703(57)\end{array}$ & $\begin{array}{l}147 \\
84 \\
6 \cdot 3 \\
1 \cdot 14 \\
25 \cdot 8 \\
263(24) \\
898(82)\end{array}$ & $\begin{array}{l}142 \\
81 \\
6 \cdot 4 \\
1 \cdot 16 \\
25 \cdot 1 \\
88(15) \\
170(29)\end{array}$ & $\begin{array}{l}145 \\
82 \\
6 \cdot 4 \\
1 \cdot 19 \\
25 \cdot 5 \\
199(21) \\
407(43)\end{array}$ & $\begin{array}{l}151 \\
85 \\
6 \cdot 3 \\
1 \cdot 23 \\
25 \cdot 8 \\
200(24) \\
591(71)\end{array}$ \\
\hline
\end{tabular}

TABLE II-Prevalence of indicators for ischaemic heart disease at first examination

\begin{tabular}{|c|c|c|c|c|}
\hline $\begin{array}{l}\text { Drinking } \\
\text { category }\end{array}$ & No & $\begin{array}{l}\text { Definite myocardial } \\
\text { infarction on } \\
\text { electrocardiography }\end{array}$ & $\begin{array}{l}\text { Angina on standardised } \\
\text { chest pain questionnaire }\end{array}$ & $\begin{array}{l}\text { Recall of a doctor's } \\
\text { diagnosis of ischaemic } \\
\text { heart disease }\end{array}$ \\
\hline $\begin{array}{l}\text { None } \\
\text { Occasional } \\
\text { Weekends: }\end{array}$ & $\begin{array}{r}466 \\
1845\end{array}$ & $\begin{array}{l}5 \cdot 6 \\
3 \cdot 3\end{array}$ & $\begin{array}{r}12 \cdot 7 \\
8 \cdot 0\end{array}$ & $\begin{array}{r}11 \cdot 1 \\
6 \cdot 0\end{array}$ \\
\hline $\begin{array}{l}1-2 \\
3-6 \\
>6\end{array}$ & $\begin{array}{r}725 \\
1234 \\
1095\end{array}$ & $\begin{array}{l}2 \cdot 1 \\
2 \cdot 8 \\
3 \cdot 5\end{array}$ & $\begin{array}{l}4 \cdot 4 \\
8 \cdot 4 \\
8 \cdot 7\end{array}$ & $\begin{array}{l}4 \cdot 4 \\
5 \cdot 5 \\
4 \cdot 5\end{array}$ \\
\hline $\begin{array}{r}\text { Daily: } \\
1-2 \\
3-6 \\
>6\end{array}$ & $\begin{array}{l}585 \\
947 \\
832\end{array}$ & $\begin{array}{l}3 \cdot 1 \\
3 \cdot 1 \\
2 \cdot 6\end{array}$ & $\begin{array}{l}6 \cdot 8 \\
5 \cdot 4 \\
9 \cdot 3\end{array}$ & $\begin{array}{l}5 \cdot 5 \\
4 \cdot 1 \\
4 \cdot 7\end{array}$ \\
\hline Total & 7729 & $3 \cdot 1$ & $7 \cdot 8$ & $5 \cdot 5$ \\
\hline
\end{tabular}

TABLE III-Alcohol intake and incidence of major ischaemic heart disease events in men with no evidence of ischaemic heart disease at first examination

\begin{tabular}{lccc}
\hline $\begin{array}{l}\text { Drinking } \\
\text { category }\end{array}$ & No & $\begin{array}{c}\text { No(\%) with ischaemic } \\
\text { heart disease }\end{array}$ & $\begin{array}{c}\text { Adjusted rate* } \\
(\%)\end{array}$ \\
\hline None & 343 & $9(2 \cdot 6)$ & $2 \cdot 6$ \\
Occasional & 1453 & $53(3 \cdot 6)$ & $3 \cdot 8$ \\
Weekends: & 607 & $16(2 \cdot 6)$ & $3 \cdot 0$ \\
$1-2$ & 980 & $29(3 \cdot 0)$ & $3 \cdot 1$ \\
$3-6$ & 849 & $24(2 \cdot 8)$ & $2 \cdot 4$ \\
$>6$ & 465 & $10(2 \cdot 2)$ & $2 \cdot 6$ \\
Daily: & 775 & $20(2 \cdot 6)$ & $2 \cdot 5$ \\
$1-2$ & 631 & $22(3 \cdot 5)$ & $3 \cdot 0$ \\
$3-6$ & 6103 & $183(3 \cdot 0)$ & \\
$>6$ & & & \\
\hline Total & & & \\
\hline
\end{tabular}

^Taking into account age, smoking years, and social class.

lipoprotein cholesterol, uric acid, and blood lead, and mean red cell volume. These findings ${ }^{6}$ strongly supported the validity of the reported alcohol consumption and the use of the eight drinking categories.

\section{SMOKING}

Smoking habits were ascertained from a standardised questionnaire. Though detailed information was obtained, in this paper we refer only to the proportion of current cigarette smokers in each drinking category and to the number of years a man had smoked (smoking years), irrespective of the quantity of cigarettes smoked.?

\section{PRESENCE OF ISCHAEMIC HEART DISEASE}

We used three sources of information about the presence of ischaemic heart disease at initial examination-namely, a standardised chest pain questionnaire for angina or possible myocardial infarction ${ }^{8} ;$ a computerised three lead orthogonal electrocardiograph to detect myocardial ischaemia or infarction ${ }^{8}$; and the subject's recall of a doctor's diagnosis of angina or myocardial infarction (heart attack, coronary thrombosis). ${ }^{9}$

\section{FOLLOW UP}

All men, whether or not they showed evidence of ischaemic heart disease at the first examination, were followed up for mortality and cardiovascular morbidity. ${ }^{10}$ The criteria for becoming a "case" of major ischaemic heart disease have been described. ${ }^{11}$ In brief, fatal cases were those coded as International Classification of Diseases 410-414 on the death certificate. Non-fatal cases of myocardial infarction had to fulfil at least two of the three standard criteria: severe prolonged chest pain, changes detectable by electrocardiography or enzymic changes. By July 1985, 335 of the 7729 men had experienced a major ischaemic heart disease event.

\section{STATISTICAL METHODS}

The simultaneous contributions of alcohol intake and other factors to the risk of severe ischaemic heart disease events were analysed by a multiple logistic model. The adjusted rates presented in the figure and table III were obtained by using such models with age and cigarette smoking (smoking years) fitted as continuous measurements and social class fitted as five dummy variables.

\section{Results}

\section{ALCOHOL INTAKE AND OTHER RISK FACTORS}

Table I shows the number and proportion of men in each of the eight categories of alcohol consumption and also gives information on the relation between the drinking categories and other potential risk factors for ischaemic heart disease.

Age-Subjects who drank heavily, either at the weekend or daily, tended to be younger than moderate or light drinkers.

Cigarette smoking - In both the weekend and daily drinking categories there was a strong association between the proportion of current cigarette 
BRITISH MEDICAL JOURNAL VOLUME $294 \quad 21$ MARCH 1987

smokers and alcohol intake. The group of light daily drinkers contained the lowest proportion of current cigarette smokers; this was true both for manual and for non-manual workers. ${ }^{12}$ The group of light weekend drinkers contained the next lowest proportion of smokers. Non-drinkers and occasional drinkers had smoking rates similar to moderate drinkers, which might reflect the previous drinking habits of these men. In both weekend and daily drinkers there was a positive association with smoking years, the lowest figure being seen in the light daily drinkers. Again, the number of smoking years for non-drinkers and occasional drinkers was similar to that in moderate drinkers.

Blood pressure-As in other studies heavy daily drinkers had significantly higher mean systolic and diastolic blood pressure than non-drinkers or occasional drinkers. Light daily drinkers had the lowest mean systolic blood pressure.

Blood lipid concentration-Serum cholesterol concentration did not show any consistent relation to alcohol intake, but the high density lipoprotein cholesterol concentration showed a consistent dose-response relation with alcohol intake.

Body mass index-There was a slight trend of increasing mean body mass index from light to heavy drinkers, but a clearer trend was seen in the proportion of men who were obese-that is, in the top fifth of the distribution of body mass index $\left(>28 \mathrm{~kg} / \mathrm{m}^{2}\right)$. Surprisingly, weekend and daily drinkers had the same mean body mass index and the same proportion classed as obese for light, moderate, and heavy drinkers.

Social class_-In both weekend and daily drinkers there was a strong and consistent trend towards a higher proportion of manual workers among groups with a greater alcohol intake. Heavy drinking was strongly associated with manual worker state. Conversely, the lowest proportion of manual workers by far occurred among light drinkers, particularly light daily drinkers. The group of non-drinkers, like heavy drinkers, also showed a predominance of manual workers.

\section{PREVALENCE OF ISCHAEMIC HEART DISEASE}

Table II shows three indicators of the presence of ischaemic heart disease-namely, definite myocardial infarction as shown on an electrocardiogram,${ }^{8}$ definite angina as ascertained by a standard questionnaire,${ }^{8}$ and recall of a doctor's diagnosis of ischaemic heart disease (angina or heart attack). ${ }^{9}$ The prevalence of all three indicators was significantly higher in non-drinkers than in those who took alcohol. Occasional drinkers had slightly higher rates of recall of a doctor's diagnosis of ischaemic heart disease than subjects in other drinking categories. No other consistent relation was seen between alcohol intake and the prevalence of ischaemic heart disease.

\section{ALCOHOL AND MAJOR ISCHAEMIC HEART DISEASE EVENTS DURING FOLLOW UP}

After the first examination 335 of the 7729 men experienced a major ischaemic heart disease event (figure). A global significance test $\left(\chi^{2}=6 \cdot 5,7\right.$ df, $p=0.5$ ) showed no evidence of a relation between alcohol intake and the attack rate of these events. Such a global test, however, lacks the statistical power to detect specific departures from the null hypothesis, and the observed univariate pattern of association therefore deserves some comment.

Daily light drinkers had the lowest attack rate. This was a fairly small group of men containing the lowest proportion of current smokers; having the lowest mean smoking years, the lowest mean systolic and diastolic blood pressures, and the lowest mean body mass index and proportion of obese subjects, and containing the lowest proportion of manual workers (table I). In the group of daily drinkers the incidence of attacks increased as daily alcohol intake increased, but the trend was not significant. The heaviest drinkers (more than six drinks daily) had the same rate of attacks as the non-drinkers and the total sample of men-that is, $4 \cdot 3 \%$. The highest attack rate occurred in the occasional drinkers.

\section{OTHER RISK FACTORS}

Logistic regression was used to calculate the adjusted percentage rates of ischaemic heart disease for each alcohol category-that is, allowing for differences in age, cigarette smoking (smoking years), and social class. We did not think that it was appropriate to adjust for blood pressure or differences in blood lipid concentration, as both could be mechanisms by which alcohol and ischaemic heart disease are associated. The figure shows the adjusted percentage rates together with the unadjusted percentage rates and their $95 \%$ confidence limits. The adjusted percentages are not substantially different from the unadjusted percentages, with no change exceeding $0 \cdot 4 \%$. The impression of a lower incidence of heart disease events in light daily drinkers is somewhat reduced after the lower prevalence of smoking and the greater proportion of manual workers in the group have

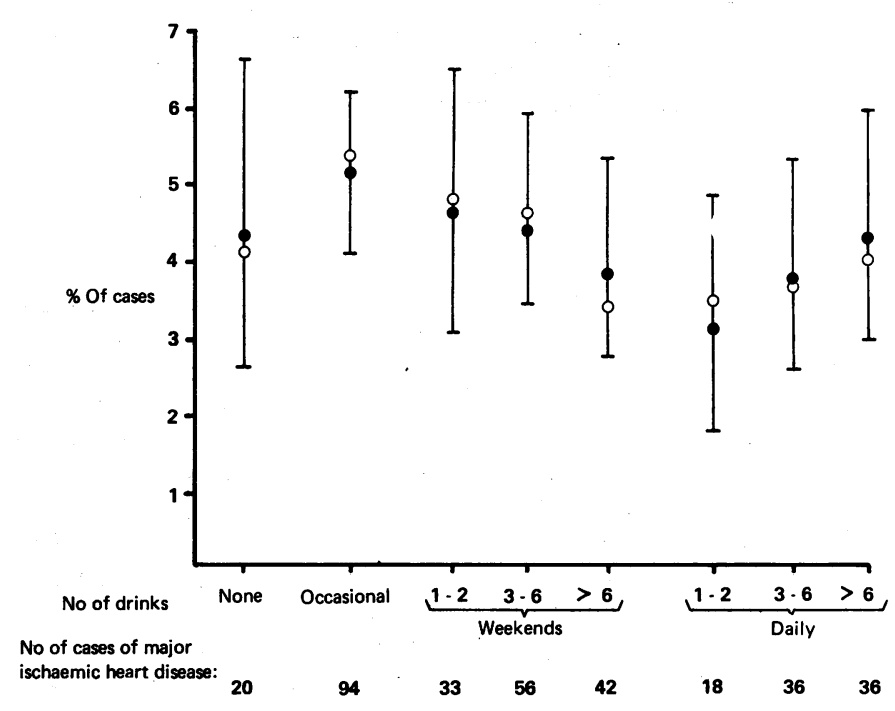

Attack rates (\%) of major ischaemic heart disease events in eight drinking categories. Bars represent $95 \%$ confidence limits for unadjusted rate $(O)$. $\mathrm{O}=$ Rate adjusted for age, smoking years, and social class.

been taken into account. Though the prevalence of ischaemic heart disease was highest among the non-drinkers (table II), this did not result in a higher rate of attacks among non-drinkers (figure), possibly because the number of men with ischaemic heart disease in the non-drinkers was too small to have a notable impact on their overall rate of attacks.

\section{INCIDENCE OF ISCHAEMIC HEART DISEASE EVENTS IN MEN WITHOUT HEART DISEASE}

Alcohol may have different effects on men with and without pre-existing ischaemic heart disease, and those who know that they have ischaemic heart disease or who have symptoms-for example, angina-may change their drinking habits. It was therefore necessary to examine the incidence of severe ischaemic heart disease events in the 6103 men who did not show evidence of ischaemic heart disease at the first examination. Men who had electrocardiographic evidence of myocardial infarction or definite ischaemia or angina as ascertained by questionnaire, or who recalled a doctor diagnosing ischaemic heart disease, were excluded.

Table III shows that, as expected, the incidence is reduced by about one third overall compared with that shown in the figure. There was no consistent relation between alcohol consumption and the incidence of severe ischaemic heart disease events, though the highest incidence was still seen in occasional drinkers.as well as in the heavy daily drinkers and the lowest in light daily drinkers. In the daily drinkers there was again a progressive increase in the incidence of severe ischaemic heart disease events with increasing alcohol intake, though this trend was not significant. When these incidences were adjusted to allow for the effects of age, smoking years, and social class the highest incidence persisted in the occasional drinkers, but the daily light drinkers no longer had the lowest incidence.

\section{Discussion}

In this large prospective study of middle aged men in Britain we found no significant association between alcohol intake and the incidence or attack rate of major ischaemic heart disease events. These findings seem to conflict with recent reviews that suggest that moderate alcohol intake protects against ischaemic heart disease. ${ }^{34}$ Though our findings do not indicate any increased incidence of ischaemic heart disease in our heaviest drinking category, we made no special effort to identify very heavy drinkers or alcoholics as has been done in some earlier studies. ${ }^{13-15}$ The findings do, however, agree with some earlier prospective studies of ischaemic heart 
disease in Britain ${ }^{16}$ and the United States, ${ }^{17}$ which showed no relation between alcohol intake and ischaemic heart disease.

One basic problem is that few studies have attempted to validate the reported alcohol intakes. Some have relied on the inclusion of alcohol intake in a 24 hour or two to three day dietary recall, which may exclude the days on which alcohol intake is most likely to take place. ${ }^{18}{ }^{19}$ Others have depended on the retrospective reporting of a dead person's alcohol intake by the surviving spouse or friends. ${ }^{20}$

\section{HEAVY DRINKERS}

There are reasons for expecting a higher incidence of ischaemic heart disease in heavy drinkers. Such a group contains a high proportion of cigarette smokers and is more likely to have increased blood pressure. A Swedish study that used registration with the Temperance Board as an indicator of heavy drinking found an increased incidence of non-fatal ischaemic heart disease and sudden cardiac death independent of blood pressure and smoking. ${ }^{14}$ Some early pathology studies, however, have suggested that heavy drinkers have less extensive atherosclerosis, ${ }^{21}$ and recent arteriography studies have shown that coronary occlusion scores are higher among non-drinkers and light drinkers than among moderate or heavy drinkers despite an increased prevalence of cigarette smoking in the heavy drinkers. ${ }^{22}$ This last finding might be associated with dietary changes likely to occur in heavy drinkers, in whom fatty meals may not be well tolerated and in whom an increasing proportion of total energy intake comes from alcohol. ${ }^{23}$ The British regional heart study shows no evidence of an increased incidence of ischaemic heart disease in the heavier drinkers despite higher mean blood pressures and a higher prevalence of cigarette smoking.

This finding clearly demands an explanation. Foremost must be the fact that our study made no attempt to identify extremely heavy drinkers; our "heavy" drinking groups included some men who would not commonly be regarded as being very heavy drinkers. Other variables affected by alcohol-for example, dietary factors, blood lipid components, and coagulation or lysis phenomena-may also offset the increased blood pressure and cigarette smoking in the heavy drinkers.

\section{DOES MODERATE ALCOHOL CONSUMPTION PROTECT AGAINST} ISCHAEMIC HEART DISEASE?

According to Turner et al, "The cumulative epidemiological evidence from a number of studies consistently confirm the existence of a negative association between moderate alcohol use and coronary heart disease (particularly myocardial infarction)"3; and Marmot said: "The evidence is far from complete; but it does point towards a protective effect of moderate alcohol consumption"4 and "The apparent protective effect is not large but the consistency of the association and the existence of plausible mechanisms increase the likelihood that the negative association is causal."4

This paper does not allow more than a brief critical comment on these two reviews, the findings of which are based mainly on seven longitudinal studies (Western Electric, ${ }^{24}{ }^{25}$ Framingham, ${ }^{26}{ }^{27}$ Honolulu, ${ }^{26}{ }^{28-30}$ Puerto Rico, ${ }^{18}{ }^{26}{ }^{31}$ Busselton, Australia, ${ }^{32}$ Whitehall, London, ${ }^{19}{ }^{33}$ and Yugoslavia ${ }^{34}{ }^{35}$ ) and one case-control study, in which alcohol intake was determined before the ischaemic heart disease event occurred (Kaiser-Permanente ${ }^{36-38}$ ). None of these studies provides biochemical or haematological validation of alcohol intake, and in many of them the grouping of subjects into drinking categories is based on limited information. In particular, the designation of "non-drinkers" is extremely loose; the overlap with occasional and even light drinkers must be considerable, and previous heavy drinking cannot be excluded.

The findings in these studies vary considerably and in most-for example, the Kaiser-Permanente, Puerto Rico, Whitehall, and Busselton studies-are based substantially on the higher incidence of cardiovascular disease in those designated as non-drinkers. The use of non-drinkers as a baseline group for comparison is fraught with problems. It is a mixed group with a varying experience of alcohol, and many have given up drinking for reasons of ill health ( $G$ Wannamethee, A G Shaper, unpublished observations). Once nondrinkers are excluded as a baseline group in these studies there is $c$ little to show that light or moderate drinking protects against $\widehat{\widehat{C}}$ ischaemic heart disease. In the Honolulu study the data suggest that there is a continuous inverse relation between heart disease and alcohol intake: the more alcohol that is drunk the lower the mortality from ischaemic heart disease. A low incidence of ischaemic heart disease in very heavy drinkers was also seen in the Yugoslavian study, but drunkenness was predictive of sudden coronary death. If anything is clear from a review of these large studies it is that there is no consistent relation between alcohol intake and ischaemic heart disease.

\section{Conclusion}

The apparent "protection" of light daily drinkers from ischaemic heart disease is more likely to be a consequence of multiple advantageous characteristics, such as low blood pressure and mean body mass index, experienced over a lifetime than a direct effect of alcohol intake. We have calculated that if a genuine effect did exist it would require a study three times the size of this one with at least three times the number of major ischaemic heart disease events to provide significant evidence of a $30 \%$ reduction in the risk of ischaemic heart disease events in light daily drinkers compared with non-drinkers or heavy daily drinkers. Even then we could not be certain that the association with alcohol was truly causal. The possible risks or benefits of alcohol must be seen in perspective. The established risk factors such as cigarette smoking, high blood pressure or serum cholesterol concentration, family history, and diabetes mellitus all outweigh any possible contribution made by alcohol to the risk of ischaemic heart disease. ${ }^{11}$

There is strong evidence that heavy drinking is associated with increased morbidity and mortality from several disorders, from hypertension and hepatic disease to psychiatric problems and road traffic accidents. The social effects, including damage to family life and work performance, are considerable. We should be extremely cautiousabout suggesting that regular drinking has health promoting attributes even though there is no evidence that light drinking carries any hazard to health. Continued support for the "protective effect of moderate alcohol consumption" should be based on stronger evidence than is at present available.

The British Regional Heart Study is a research group of the British Heart Foundation and also receives grants from the Medical Research Council and the Department of Health and Social Security. The Institute of Alcohol Studies provides support for those studies relating to the effects of alcohol

\section{References}

1 Brigden W, Robinson J. Alcoholic heart disease. BrMed $\mathcal{F}$ 1964;ii:1283-9.

2 Klatsky AL, Freedman GD, Siegelaub AB, Gerard HJ. Alcohol consumption and blood pressure. Kaiser-Permanente Multiphasic Health Examination Data. N Engl f Med 1977;296:1194-9.

3 Turner TB, Bennett VL, Hernandez H. The beneficial side of moderate alcohol use. Fohn Hopkins Medical foumal 1981;148:53-63.

4 Marmot MG. Alcohol and coronary heart disease. Int f Epidemiol 1984;13:160-7.

5 Shaper AG, Pocock SJ, Walker M, Cohen NM, Wale CJ, Thomson AG. British regional heart study: cardiovascular risk factors in middle aged men in 24 towns. Br Med $\mathcal{F} 1982 ; 283: 179-86$.

6 Shaper AG, Pocock SI, Ashby D, Walker M, Whitehead TP. Biochemical and haematological response to alcohol intake. Ann Clin Biochem 1985;22:50-61.

7 Cook DG, Shaper AG, Pocock SJ, Kussick SJ. Giving up smoking and the risk of heart attacks. A report from the British regional heart study. Lancet 1986;ii:1376-80.

Shaper AG, Cook DG, Walker M, Macfarlane PN. Prevalence of ischaemic heart disease in middle-aged British men. Br Heart $\mathcal{f}$ 1984;51:595-605.

9 Shaper AG, Cook DG, Walker M, Macfarlane PW. Recall of diagnosis by men with ischaem heart disease. Br Heart f 1984;51:606-11.

10 Walker $M$, Shaper AG. Follow-up of subjects in prospective studies in general practice. $\mathcal{f} R$ Coll Gen Pract 1984;34:365-70.

11 Shaper AG, Pocock SJ, Walker M, Phillips A, Whitehead TP; Macfarlane PW. Risk factors for ischaemic heart disease: the prospective phase of the British regional heart study. $\mathcal{F}$ Epidemiol ischaemic heart disease: the prosp

12 Cummins RO, Shaper AG, Walker M, Wale CJ. Smoking and drinking by middle-aged British men: effects of social class and town of residence. $B r M e d ~ f 1981$;283:1497-502.

13 Wilhelmsen L, Wedal H, Tibblin G. Multivariate analysis of risk factors for coronary heart disease. Circulation 1973;48:950-8.

14 Tibblin G, Wilhelmsen L, Werko L. Risk factors for myocardial infarction and death due to ischemic heart disease and other causes. Am $\mathcal{F}$ Cardiol 1975;35:514-22. 
15 Hrubec $Z$, Cederlof R, Friberg $L$. Background of angina pectoris: social and environmental factors in relation to smoking. Am $\mathcal{J}$ Epidemiol 1976;103:16-29.

16 Morris JN, Kagan A, Patterson DC, et al. Incidence and prediction of ischaemic heart disease in London busmen. Lancet 1966;ii:553-9.

17 Doyle JT, Heslem AS, Hilleboe HE, et al. A prospective study of degenerative cardiovascular disease in Albany: report of three years' experience. Ischemic heart disease. Am 7 Public Health disease in Albany: repo:t

18 Kittner SJ, Garcia-Palmieri MR, Costas R, Cruz-Vidal M, Abbott RD, Havlik RJ. Alcohol and coronary heart disease in Puerto Rico. Am F Epidemiol 1983;117:538-50.

19 Marmot MG, Rose G, Shipley MJ, Thomas BJ. Alcohol and mortality: a U-shaped curve. Lance 1981;i:580-3.

20 Hennekens $\mathrm{CH}$, Rosner B, Cole DS. Daily alcohol consumption and fatal coronary heart disease. Am $\mathcal{F}$ Epidemiol 1978;107:196-200.

21 Cabot RC. The relation of alcohol to arteriosclerosis. JAMA 1904;43:774-5.

22 Barboriak JJ, Rimm AA, Anderson AJ, et al. Coronary artery occlusion and alcohol intake. Br Hear f 1977;39:289-93.

23 Jones BR, Barret-Connor E, Criqui MH, Holdbrook MJ. A community study of calorie and nutrient intake in drinkers and non-drinkers of alcohol. Am 7 Clin Nutr 1982;35:135-9.

24 Dyer AR, Stamler J, Lepper MH, Shekelle RB, McKean H, Garside D. Alcohol consumption and 17-year morbidity in the Chicago Western Electric Co study. Prev Med 1980;9:78-90.

25 Dyer AR, Stamler J, Paul O, et al. Alcohol, cardiovascular risk factors and mortality; the Chicago experience. Circulation 1981;64 (suppl 111):20-7.

26 Gordon T, Kagan A, Garcia-Palmieri M, et al. Diet and its relation to coronary heart disease and death in three populations. Circulation 1981;63:500-15.

27 Gordon T, Kannel WB. Drinking habits and cardiovascular disease: the Framingham study. Am Heart f 1983;105:667-77.
28 Yano K, Rhoads GG, Kagan A. Coffee, alcohol and risk of coronary heart disease among Japanese men living in Hawaii. N Engl I Med 1977;279:405-9.

29 Blackwelder WC, Yano K, Rhoads GG, Kagan A, Gordon T, Palesch Y. Alcohol and mortality: the Honolulu heart study. Am f Med 1980;68:164-9.

30 Kagan A, Yano K, Rhoads GG, McGee DL. Alcohol and cardiovascular disease: the Hawaiian experience. Circularion 1981;64 (suppl 111):27-31.

31 Garcia-Palmieri MR, Sorlie P, Tillotson J, Costas R, Cosdero E, Rodriguez M. Relationship of dietary intake to subsequent coronary heart disease incidence: the Puerto Rico heart health program. Am $\mathcal{J}$ Clin Nutr 1980;33:1818-27.

32 Cullen K, Stenhouse NS, Wearne KL. Alcohol and mortality in the Busselton study Int $\mathcal{J}$ Epidemiol 1982;11:67-70.

33 Marmot MG, Rose G, Shipley MJ. Alcohol and mortality. Lancet $1981 ; 1: 1159$

34 Kozarevic DJ, McGee D, Vojrvodic N, et al. Frequency of alcohol consumption and morbidity and mortality: the Yugoslavia cardiovascular disease study. Lancet 1980;i:613-6.

35 Kozarevic D, Demirovic J, Gordon T, Kaelber CT, McGee D, Zukel WJ. Drinking habits and coronary heart disease: the Yugoslavia cardiovascular disease study. Am f E pidemiol 1982;116: 748-58.

36 Klatsky AL, Friedman GO, Siegelaub AB. Alcohol and mortality. A ten-year Kaiser-Permanente experience. Ann Intern Med 1981;95:139-45.

37 Klatsky AL, Friedman GO, Siegelaub AB. Alcohol consumption before myocardial infarction: results from the Kaiser-Permanente study of myocardial infarction. Ann Intern Med 1974;81: 294-301.

38 Klatsky AL, Friedman GD, Siegalaub MS. Alcohol use and cardiovascular disease: the Kaiser Permanente experience. Circulation 1981;64 (suppl 111):32-41.

(Accepted 5 February 1987)

\title{
Congenital rubella in babies of south Asian women in England and Wales: an excess and its causes
}

\author{
ELIZABETH MILLER, ANGUS NICOLL, STEPHEN A ROUSSEAU, PETER J L SEQUEIRA, \\ MILTON H HAMBLING, RICHARD W SMITHELLS, HELEN HOLZEL
}

\begin{abstract}
The incidence of congenital rubella was found to be 2.3 times higher in Asian than non-Asian births in England and Wales. This was attributed in part to higher susceptibility to rubella in Asian than non-Asian women, as shown by antenatal serological data from public health laboratories in Leeds, Luton, and Manchester. Examination of the ethnic origin of pregnant women requesting laboratory testing after contact with rubella or rash and of women with laboratory confirmed rubella in pregnancy also suggested that the disease was being underdiagnosed in pregnant Asian women. Failure to prevent congenital rubella by termination of infected pregnancies may therefore contribute to the increased incidence of the syndrome in Asians.
\end{abstract}

PHLS Communicable Dísease Surveillance Centre, London NW9 5HT ELIZABETH MILLER, MB, BSC, principal microbiologist

University of Nottingham, Department of Child Health, Queen's Medical Centre, Nottingham NG7 2UH

ANGUS NICOLL, MRCP, lecturer in child health

Public Health Laboratory, Luton and Dunstable Hospital, Luton LU4 0DZ STEPHEN A ROUSSEAU, MRCPATH, DOBSTRCOG, consultant microbiologist

Central Serology Laboratory, Withington Hospital, Manchester M20 8LR PETER J L SEQUEIRA, MB, BS, laboratory director

Public Health Laboratory, Leeds LS15 7TR

MILTON H HAMBLING, MD, FRCPATH, consultant microbiologist

Department of Paediatrics and Child Health, Clarendon Wing, General Infirmary, Leeds LS2 9NS

RICHARD W SMITHELLS, FRCP, DCH, professor of paediatrics

Hospital for Sick Children, Department for Microbiology, Great Ormond Street, London WC1 3JH

HELEN HOLZEL, MD, MRCPATH, consultant microbiologist

Correspondence and requests for reprints to: Dr Miller.
Health education programmes about the dangers of rubella in pregnancy and of the need for vaccination can readily be promoted in the Asian community through existing ethnic organisations. Protection of other ethnic minorities likely to be at similar increased risk may require a vaccination programme aimed at national elimination of rubella.

\section{Introduction}

Congenital rubella is a cause of severe and permanent disability. An affected child is distressing and burdensome for the family and usually requires lifelong support of health and educatiunal services. Unlike other types of severe handicap, the cause of this condition is both known and preventable, either by vaccination or by terminating infected pregnancies.

The British rubella vaccination policy is to immunise selectively girls while at school and non-immune adult women before or after pregnancy. It is therefore important to seek out and concentrate resources on those women most likely to be at risk. A study at a London antenatal clinic showed one such group to be ethnic south Asians (immigrants from India, Pakistan, Bangladesh, or Sri Lanka or east African Asians; for simplicity referred to here as Asians), since susceptibility to rubella was higher in these patients than in non-Asian women. ${ }^{1}$ We have investigated this finding by comparing susceptibility in Asian and non-Asian antenatal patients elsewhere in Britain. We have also compared the incidence of confirmed rubella infection in pregnancy as well as that of notified congenital rubella in Asian and non-Asian births in England and Wales.

\section{Subjects and methods}

Data on susceptibility to rubella according to age, parity, and ethnic group were obtained for antenatal patients screened by Public Health Laboratory Service laboratories in Manchester, Leeds, and Luton. Since 1984 each laboratory has obtained information on parity for antenatal patients as part of a Public Health Laboratory Service serological surveillance programme. ${ }^{2}$ 